\title{
Giant Cell Arteritis of the Breast
}

Nur BÜYÜKPINARBAŞILI', Zühal GÜCIN'1', Yeliz Emine ERSOY², Şeyma YILDIZ ${ }^{3}$

'Department of Pathology, Bezmialem Vakif University School of Medicine, İstanbul, Turkey

${ }^{2}$ Department of General Surgery, Bezmialem Vakif University School of Medicine, İstanbul, Turkey

${ }^{3}$ Department of Radiology, Bezmialem Vakif University School of Medicine, İstanbul, Turkey

\section{ABSTRACT}

Systemic vasculitis such as Wegener's granulomatosis (WG), giant cell arteritis (GCA), and poliarteritis nodosa (PAN) may produce tumorlike masses in various organs. GCA may affect large vessels and also rarely present with primary visceral involvement in the breast. In these situations, GCA may confuse with malignancy because of characteristics such as tenderness, redness, and mass formation. This article presents a case report on an 87-year-old woman with palpable mass in her breast and was diagnosed as GCA in the biopsied lesion.

Keywords: Breast, mass, giant cell arteritis

\section{Introduction}

Systemic vasculitis, such as Wegener's granulomatosis (WG), giant cell arteritis (GCA), and polyarteritis nodosa (PAN), may cause tumor-like formations in organs. Among these conditions, GCA may rarely be seen in the breast as the primary organ involvement $(1,2)$. Concomitant sensitivity, redness, and palpable masses can be detected in the breast, and they can be confused with malignancy (2). Between 1980 and 2010, a total of 21 cases were reported in the literature. These are the cases presenting with primary breast involvement. We aimed to present a case of GCA in the breast because it rarely occurs and manifests itself in the form of a mass that may be confused with malignancy.

\section{Case Report}

An 87-year-old female patient applied to our clinic complaining of a palpable mass in the right breast since 3 months. Laboratory examinations had no abnormal findings. The anamnesis revealed no feature except hypertension. On physical examination, nodularity and tenderness in the breast were detected. On mammographic examination, calcifications with cluster formations were revealed (Figure 1). All these areas were removed using a vacuum core biopsy. Histopathological examination of the material revealed fragmentation in the lamina in medium-sized elastic arteries, inflammatory infiltration composed of multinucleated giant cells and mononuclear cells (Figure 2), and intimal thickening and dystrophic calcification (Figure 3, 4). The patient was diagnosed with GCA based on these findings. No symptoms of internal organ involvement or temporal arteritis were detected during the system examination. After observing in the control mammography that the entire lesion was removed, the patient was taken for follow-up. No additional findings were detected at the 1-year follow-up.

\section{Discussion}

Systemic vasculitis can form tumor-like formations. Of these, GCA is usually localized in the external carotid artery and its branches and is often known as temporal arteritis associated with the localization. It occurs in 


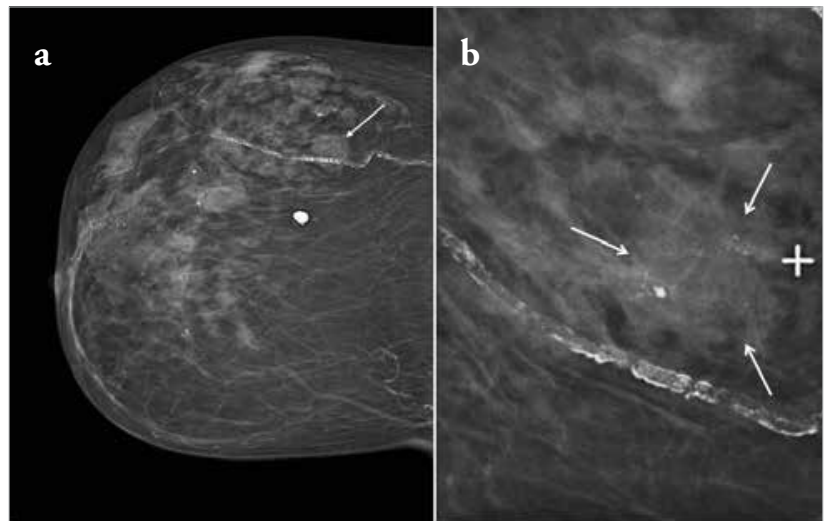

Figure 1. a, b. Mammographic image of the right breast taken in craniocaudal position; (a) an increase in asymmetric density in the size of 20x15 mm accompanied by thin pleomorphic microcalcifications is observed (arrow). In the enlarged image of this area; (b) microcalcifications can be observed better

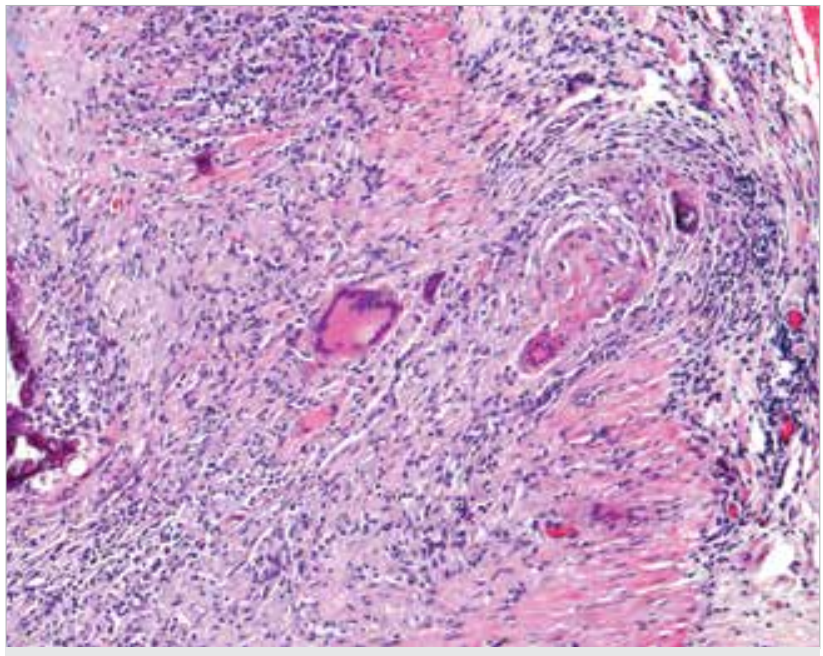

Figure 2. Infiltration consisting of giant cells and mononuclear cells in the vessel wall (H-EX200)

the aorta and upper-lower extremity arteries at a ratio of $10-30 \%(3)$. When seen as the primary organ involvement in the breast, tenderness, redness, and palpable masses can be detected and therefore may be confused with malignancy.

Most patients are elderly postmenopausal women. In addition to rheumatic polymyalgia symptoms, such as mild fever, arthralgia, and myalgia, findings related to the breast should suggest GCA. However, a definitive diagnosis can be made by pathological examination $(1,4)$. Microscopically, fragmentation of the elastic lamina of the vessel wall, giant cell infiltration, intimal proliferation, and narrowing of the lumen can be observed (1).

Distinct findings and masses are generally not found in mammography and ultrasound radiologically $(1,2)$. String-like thickening and hypoechoic circumscribed

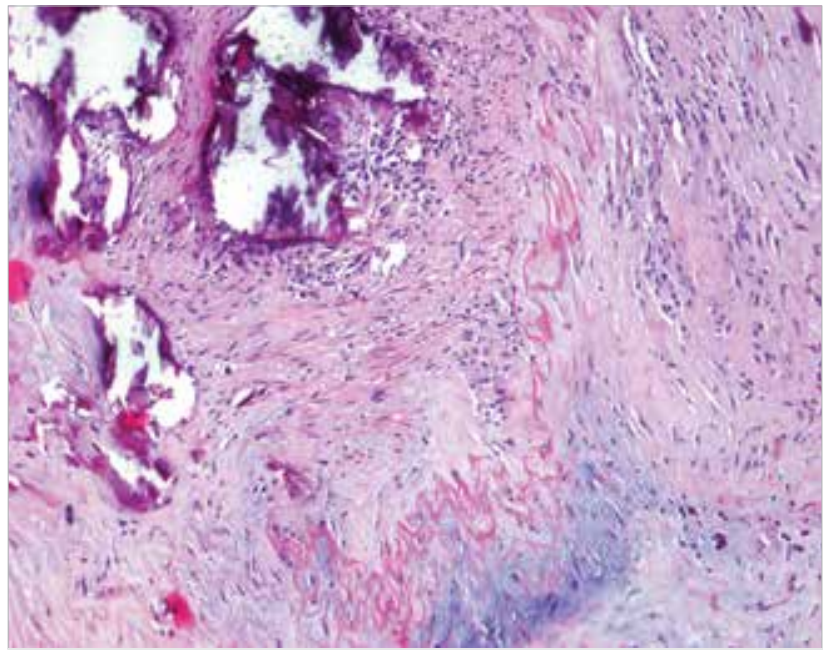

Figure 3. The presence of dystrophic calcification in the vessel wall (H-EX200)

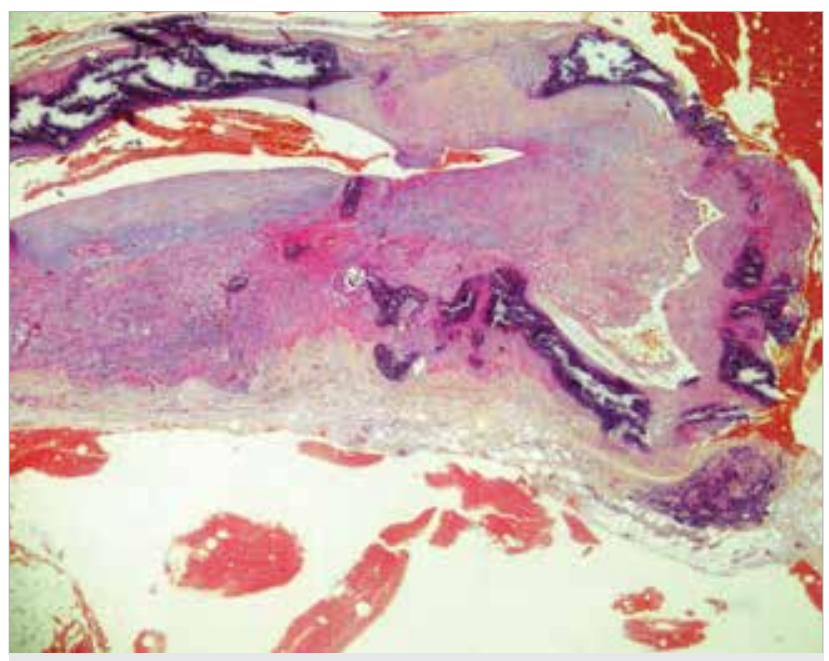

Figure 4. Extensive dystrophic calcification in the vessel wall (H-EX100)

as the halo symptom, were reported in one patient (1). Diagnosis can rarely be approached with systemic symptoms and ultrasonography findings before the biopsy. In most cases, when viewed retrospectively after pathologic diagnosis, the presence of systemic rheumatic symptoms draws attention. Therefore, a clinical suspicion and a further investigation are necessary to avoid the invasive radical approaches $(4,5)$.

In breast GCA patients, an ovarian mass may be the real cause of admission to the hospital. The cases emerging in this way are included in differential diagnosis with PAN (5). At the same time, the relationship between cancer and GCA is emphasized and it is reported that symptoms of vasculitis disappear after the removal of the tumor mass in patients with invasive ductal carcinoma (6).

Treatment using prednisone is preferred in patients with GCA. It ensures improvement both in systemic symp- 
toms and symptoms in the breast (1). In addition, it was reported that the use of drugs such as aspirin at low doses significantly decreased ischemic complications observed during the course of the decrease (7). Aspirin constitutes the main effect by reducing the immunemediated inflammation and degrading the damage in the vascular wall (8). Use of methotrexate is also among the treatment options. When added to the treatment, it becomes possible to reduce the dose of glucocorticoids, thereby reducing the possible side effects (9). Most patients recover with medical treatment. Surgery is a preferred option in limited cases. Surgery is implemented especially in developing symptomatic aneurysms in large vessel involvements. In the case of the development of artery stenosis other than this, interventions such as "stent," "bypass," or "angioplasty" can be applied (10). Most interestingly, even if no treatment applied, spontaneous remission can be seen in some patients (2). After the lesion area was removed in our patient, recurrence or other organ involvement was not seen. Because there was no other organ involvement in the patient except for the breast, corticosteroids or other treatment options were not preferred.

\section{Conclusion}

Vasculitides usually do not cause difficulties in diagnosis. However, when they constitute organ involvements and present with palpable masses, they may be confused with malignancy. Considering vasculitides during the differential diagnosis of tumor-like masses allows the avoidance of unnecessary surgical procedures.

Informed Consent: Due to the retrospective nature of this study, informed consent was waived.
Peer-review: Externally peer-reviewed.

Author Contributions: Concept - N.B., Z.G., Y.E.E., Ş.Y.; Design - N.B., Z.G., Y.E.E., Ş.Y.; Supervision - N.B., Z.G., Y.E.E., Ş.Y.; Resources - N.B., Z.G.; Materials - N.B., Z.G., Y.E.E., Ş.Y.; Data Collection and/or Processing - N.B., Z.G.; Analysis and/or Interpretation - N.B., Z.G.; Literature Search - N.B., Z.G.; Writing Manuscript - N.B., Z.G.; Critical Review - N.B., Z.G.

Conflict of Interest: No conflict of interest was declared by the authors.

Financial Disclosure: The authors declared that this study has received no financial support.

\section{References}

1. Kawasaki A, Purvin V. Giant cell arteritis: an updated review. Acta Ophthalmol 2009; 87: 13-32. [CrossRef]

2. Kadotani Y, Enoki Y, Itoi N, Kojima F, Kato G, Lee CJ. Giant cell arteritis of the breast: a case report with a review of literatures. Breast Cancer 2010; 17: 225-32. [CrossRef]

3. Marie I, Audeguy P, François A, DE Kergal F, Richard C. Giant cell arteritis presenting as a breast lesion: report of a case and review of the literature. Am J Med Sci 2008; 335: 489-91. [CrossRef]

4. Anim JT, Van Herk EJ. Giant cell arteritis of the breast. Med Princ Pract 2004; 13: 234-6. [CrossRef]

5. Kariv R, Sidi Y, Gur H. Systemic vasculitis presenting as a tumorlike lesion. Four case reports and an analysis of 79 reported cases. Medicine (Baltimore) 2000; 79: 349-59. [CrossRef]

6. Kafantari E, Sotiropoulou M, Sfikakis P, Dimitrakakis K, Zagouri F, Mandrekas K, et al. Giant cell arteritis of the breast and breast cancer: paraneoplastic manifestation or concomitant disease? A case report. Onkologie 2008; 31: 685-8. [CrossRef]

7. Bnaya A, Nesher G, Sonenblick M, Breuer GS. Giant cell arteritis--old questions, current answers. Harefuah 2014; 153: 747-51.

8. Mollan SP, Sharrack N, Burdon MA, Denniston AK. Aspirin as adjunctive treatment for giant cell arteritis. Cochrane Database Syst Rev 2014; 8: CD010453. [CrossRef]

9. Schirmer M, Dejaco C, Schmidt WA. Giant-cell arteritis: update: diagnosis and therapy. Z Rheumatol 2012; 71: 754-9. [CrossRef]

10. Ponte C, Rodrigues AF, O'Neill L, Luqmani RA. Giant cell arteritis: Current treatment and management. World J Clin Cases 2015; 3: 484-94. 